\title{
UTILIZAÇÃO DO TEATRO DE TEMÁTICA CIENTÍFICA COMO FORMA DE DIVULGAR A CIÊNCIA NA EDUCAÇÃO BÁSICA
}

\section{THE USE OF SCIENTIFIC THEMATIC THEATER AS A WAY TO DISCLOSE SCIENCE IN BASIC EDUCATION}

\author{
PEREIRA, Ademir de Souza ${ }^{1}$ \\ CALIXTO, Vivian dos Santos ${ }^{2}$
}

\begin{abstract}
RESUMO
Por meio deste texto apresentamos os resultados inerentes ao desenvolvimento de ações vinculadas a um projeto de extensão intitulado Show da Química: a divulgação científica por meio do teatro de temática científica. O projeto é decorrente de uma proposta desenvolvida por professores da Universidade Federal da Grande Dourados e teve como intencionalidade apresentar aos alunos da Educação Básica atividades lúdicas por meio de encenações de teatro, que tencionou potencializar o interesse em aprender ciências. Participaram deste projeto trinta alunos dos cursos de Bacharelado e Licenciatura em Química, além de alunos vinculados ao programa de Pós-graduação em Química, do programa de Pós-graduação em Ciência e Tecnologia Ambiental e além de quatro professores com formação na área de Ensino de Química. Como resultado foram elaboradas dez peças teatrais, encenadas ao longo de 29 apresentações em escolas da cidade de Dourados e de Mato Grosso do Sul, encontros de formação inicial e continuada de professores e abertura de eventos científicos. Compreendemos que o desenvolvimento das ações correlatas ao projeto potencializou o trabalho em ambas dimensões da formação de professores, inicial e continuada, oportunizando a apropriação da linguagem científica e dos diferentes saberes inerentes a ação docente.
\end{abstract}

PalaVras ChaVe: Encenações teatrais; Divulgação científica; Teatro científico.

\section{ABSTRACT}

Through this text we present the results of the extension project entitled Show of Chemistry: scientific dissemination through the thematic theater. The project is the result of a proposal

\footnotetext{
${ }^{1}$ Doutorando do Programa de Pós-graduação em Educação para a Ciência da Universidade Estadual Paulista "Júlio de Mesquita Filho" (UNESP/Bauru). Docente do curso de Licenciatura em Química da Faculdade de Ciências Exatas e Tecnologias da Universidade Federal da Grande Dourados. MS, Brasil, ORCID: https://orcid.org/0000-0002-3635-7349 .e-mail: ademirpereira@ufgd.edu.br

2 Doutoranda do Programa de Pós-graduação em Educação para Ciência e a Matemática na Universidade Estadual de Maringá (UEM). Docente do curso de Licenciatura em Química da Faculdade de Ciências Exatas e Tecnologias da Universidade Federal da Grande Dourados. MS, Brasil. e-mail: viviancalixto@ufgd.edu.br
} 
DOI: $10.12957 / \mathrm{e}-\mathrm{mosaicos} .2019 .38208$

developed by professors of the Federal University of Grande Dourados and aims to present to students of Basic Education fun activities through theater plays, intending to enhance their interest in learning science. Thirty students from the Bachelor's and Bachelor's degree courses in Chemistry participated in this project, as well as students linked to the Graduate Program in Chemistry and the Postgraduate Program in Environmental Science and Technology, as well as four professors with a background in Teaching Chemistry. As a result, ten theatrical pieces were staged during 29 presentations at schools in the city of Dourados and Mato Grosso do Sul, meetings for initial and continuing teacher training and official openings of scientific events. We understand that the development of the actions related to the project has potentiated the work in both dimensions of teacher training, initial and continued, allowing the appropriation of scientific language and the different knowledge inherent to the teaching activity.

KEYWORDS: Theater performances; Scientific divulgation; Scientific theater.

\section{INTRODUÇÃo}

O projeto de extensão, intitulado como "Show da Química: Divulgação Científica por meio de encenações de Teatro", apresentado e discutido neste trabalho, tem sua gênese atrelada a iniciativa de um grupo de professores da área de ensino de química do curso de Licenciatura em Química da Faculdade de Ciências Exatas (FACET) da Universidade Federal da Grande Dourados (UFGD), com a intencionalidade de trabalhar com a divulgação e disseminação da linguagem científica para a comunidade interna e externa a Universidade, tencionando, por meio desse processo levar informações da ciência perante a comunidade acadêmica e escolar. Utilizamos como meio de divulgação o teatro de temática científica.

Nesse ínterim, estruturaram o planejamento do projeto as seguintes ações: a) seleção e teste de experimentos; b) desenvolvimento de narrativas; c) ensaios e adaptações; d) encenações e; e) avaliação das encenações e readaptações. As encenações teatrais, permeadas pela apresentação de experimentos, com posterior explicação dos conteúdos científicos, além de objetivar proporcionar uma apropriação da linguagem científica pelos espectadores, constitui-se por uma dimensão lúdica. Cabe ressaltar que o caráter lúdico, em diferentes ênfases têm sido, frequentemente, utilizado na área de ensino de ciências com a objetivo de potencializar o interesse em aprender.

No que se concerne a seleção dos experimentos gostaríamos de destacar que os critérios centraram-se a partir do impacto visual produzido pelos mesmos, ou seja, mudança de coloração, combustão e liberação de gases, aspectos que evidenciassem explicitamente uma reação química. Além de adequarem-se a estrutura da narrativa da peça e não oferecessem nenhum tipo de risco aos envolvidos na encenação.

As atividades que envolvem encenações teatrais que tencionem a divulgação científica já vêm sendo desenvolvidas na UFGD, por alunos do PIBID e acadêmicos da graduação de componentes curriculares de Estágio em Ensino I, II, III e IV. 
DOI: $10.12957 / \mathrm{e}-\mathrm{mosaicos} .2019 .38208$

Compreendemos que o teatro científico constitui-se como uma ferramenta potente na promoção na curiosidade epistemológica por aprender Ciência e Química, argumentamos em prol de sua potencialidade na desmistificação das visões distorcidas sobre ciência e na divulgação científica perante os estudantes da Educação Básica e da própria Universidade.

As ações desenvolvidas no âmbito do projeto tem por objetivo fortalecer o processo de formação inicial por meio das seguintes dimensões: a) formação com caráter indissociável entre ensino, pesquisa e extensão; b) desenvolvimento dos saberes inerentes a ação; c) inserir a perspectiva lúdica em atividades experimentais demonstrativas a ser desenvolvidas em sala de aula; d) proporcionar aos participantes desenvolver atividades de adequação da linguagem científica com a intencionalidade de torná-la mais acessível; e) estimular o caráter investigativo dos acadêmicos durante os testes dos experimentos, pois nesse processo há exigência do domínio do conhecimento teórico, como por exemplo; f) divulgar o curso de Química para os vestibulandos e demais alunos do Ensino Médio. Além disso a proposta engloba a formação continuada de professores de química da Educação Básica, com a seguintes contribuições: intensificar as discussões acerca da divulgação científica; apropriação de gêneros discursivos como os propostos nas peças teatrais; readaptação de propostas experimentais e reconhecimento de estratégias didáticas diferenciadas.

Diante do exposto o objetivo central deste artigo, abordado no formato de um relato de experiência, é apresentar e discutir como o Projeto de Extensão Show da Química, difundiu atividades de teatro com temática científica na região da Grande Dourados.

\section{O Projeto de Extensão Show da Química}

No âmbito da educação escolar existe uma diversidade de proposições pedagógicas e atividades, tais como: o estabelecimento de vínculos entre os estudantes e o objeto de estudo, projetos de investigação, excursões exploratórias, trabalhos em grupo, jogos didático-pedagógicos, pesquisas na internet e em bibliotecas, dentre outras atividades, nas quais os estudantes possam sentir-se estimulados a escolher temáticas, apresentar e debater opiniões divergentes e a propor possíveis caminhos para a resolução de problemas em investigação. Tais estratégias de ensino e aprendizagem podem mobilizar 0 envolvimento dos estudantes nas aulas, mas não garantem por si só que a motivação deles seja atingida.

Essa motivação ou desmotivação em sala de aula se agrava também a partir do que Babin e Koulumdjian (1989) previam decorrente das mídias e o emprego de aparelhos eletrônicos na vida cotidiana concorreriam com o interesse do aluno em sala de aula. Atualmente é possível verificar o crescente interesse dos alunos pela internet, por meio de aparelhos celulares e o pouco interesse por assuntos referentes 
DOI: $10.12957 / \mathrm{e}-\mathrm{mosaicos} .2019 .38208$

ao contexto da sala de aula. Aspecto que se agrava em componentes curriculares de ciências exatas como os referentes a Química, Física e Matemática que apresentam um alto índice de reprovação.

Nesse ínterim, esse projeto teve como ação de extensão apresentar aos alunos da Educação Básica atividades lúdicas por meio de encenações de teatro de forma a criar condições para potencializar o interesse em aprender ciências, nesse caso, especificamente, a química. Dessa maneira, o enfoque principal das ações foi o desenvolvimento de atividades experimentais em química que realizadas por um grupo de professores, graduandos e pós-graduandos em química da Universidade.

Como citado, anteriormente é perceptível e foco de algumas investigações a desmotivação dos alunos da Educação Básica pela química. Segundo Pintrich e Schunk (2006) a motivação é o processo que nos dirige para o objetivo ou meta, que instiga e mantém nossa atividade. Na perspectiva defendida por esses autores a motivação é principalmente um processo, e não simplesmente um resultado, mediante determinado estímulo.

Considerada em termos processuais, a motivação não é diretamente observável, sendo necessário inferir a partir de determinados comportamentos como a escolha entre atividades distintas, o esforço, a persistência, e a expressão dos sujeitos.

Fazer com que o aluno se interesse em aprender química é considerado em muitos casos, um desafio para o professor no Ensino Médio. No entanto, o desinteresse por essa ciência pode estar relacionado a maneira pela qual são conduzidas as atividades em sala de aula (CHASSOT, 2003). Dessa forma, elencamos como alternativa a realização de atividades que possam ser estimulantes para criar um ambiente de aprendizagem favorável ao desenvolvimento do ensino e do aprendizado.

As atividades lúdicas apresentam um aspecto que podem envolver os alunos durante as atividades de sala de aula. Assim, o teatro pelo seu perfil lúdico e envolvente, pode se constituir em um caminho capaz de sensibilizar os estudantes, a dinamizar novas ideias, a fortalecer valores pessoais e sociais, potencializar talentos, a acessar novos saberes e conhecimentos científicos. Conforme Japiassu:

Teatro é uma palavra também de origem grega cujo significado é lugar de onde se vê. Isso implica do ponto de vista que interessa aqui, entendermos a teatralidade como espetacularidade tipicamente humana, uma espetacularidade que se oferece deliberadamente (intencionalmente) à fruição e à apreciação estética (sensorial) (JAPIASSU, 2001, p. 5). 
O teatro é uma ferramenta didática em potencial, quando aplicada no ambiente de ensino e aprendizagem, pois, é capaz de direcionar o olhar dos estudantes sobre a realidade em questão. Quando aplicado ao ensino por meio de experimentos, é possível prever que os alunos poderão se interessar mais e dessa maneira sejam motivados para entender a situação ocorrida. Além disso, o teatro aplicado a este contexto, possibilita uma interação entre o aluno e o conteúdo a ser trabalhado.

No que concerne a elaboração de atividades que envolvam teatro, podemos centrar as atividades em valores que hoje em dia são esquecidos, conforme Iturbe (2007) argumenta, como a repetição, paciência, trabalho em equipe, apoio mútuo, momentos de monotonia, perseverança e principalmente a dedicação, pois o trabalho geralmente leva tempo para obter resultados. Segundo Spolin,

(...) todas as pessoas são capazes de improvisar, além disto, as pessoas aprendem através da experiência. Experienciar é se envolver total e organicamente com o ambiente. Este envolvimento se dá em todos os níveis, intelectual, físico e intuitivo. O intuitivo, o mais vital para a situação de aprendizado é geralmente negligenciado. $O$ jogo teatral propicia este envolvimento e ao mesmo tempo a liberdade para a experiência (SPOLIN, 1998, p. 3).

Os experimentos foram realizados com acompanhamento de vinhetas e música, argumenta. Cardoso (2000) elucida que a utilização de experimentos demonstrativos associados à vinhetas e animações estimulam tanto a percepção visual quanto a auditiva. Além disso, quando alinhados a divulgação científica, poderão abordar de forma acessível e didática; o que torna a situação em potencial para que possa ocorrer o aprendizado de conceitos químicos e a desmistificação da ciência.

As atividades apresentadas nesse projeto, vem ao encontro dos princípios inerentes a indissociabilidade entre ensino, pesquisa e extensão, pois proporciona ao licenciando uma atuação junto aos alunos do ensino básico e com a comunidade escolar. Desta maneira o acadêmico terá a oportunidade atuar antes mesmo do Estágio, na Educação Básica.

Sua ênfase no ensino insere-se na atuação dos acadêmicos tanto no âmbito dos componentes curriculares que se beneficiam das ações propostas no projeto, quanto no desenvolvimento e apropriação de saberes inerentes a sua formação enquanto futuro professor. Pois ao selecionar o material, as vidrarias, os reagentes, estudar o conteúdo trabalhado nos componentes curriculares de práticas de ensino de química e adequar todo os roteiros para que seja realizado em sala de aula na Educação Básica tais dimensões são contempladas. Além disso, o foco no ensino 
DOI: $10.12957 /$ e-mosaicos.2019.38208

também está presente quando os acadêmicos participaram das reuniões de orientação e na sequência elaboraram atividades de microensino que envolvam a adequação das explicações dos experimentos.

A pesquisa com enfoque no ensino, foi realizada por meio da observação direta da percepção dos alunos da Educação Básica sobre as atividades desenvolvidas na escola. Principalmente no que se refere a realização de atividades lúdicas com a participação dos estudantes. Além disso, foram aplicados questionários avaliativos para os professores e estudantes da Educação Básica com o objetivo de investigar se houve entendimento dos conceitos trabalhados durantes as atividades.

Outro fator, relevante, que enfoca o caráter de pesquisa é a investigação dos alunos acerca dos experimentos a serem realizados no laboratório. Além disso professores sugeriam alterações nos roteiros e ao mesmo tempo poderiam ser realizadas pesquisas educacionais sobre os conteúdos que os alunos mais tem dificuldades na educação básica referente ao conteúdo de Química para que servissem de informações para futuras intervenções por meio de peças teatrais.

A atividade expressa o seu caráter extensionista, ao levar por meio de peças teatrais a divulgação do conhecimento cientifico em Química nas escolas localizadas na região da Grande Dourados, composta por doze cidades que circundam Dourados. Por meio desta proposta o ensino, a pesquisa e a extensão estão caracterizados por meios das ações que são apresentadas ao longo da metodologia deste trabalho.

\section{Procedimentos metodológicos}

Este artigo consiste em um relato de experiência vivenciado pelos autores durante todo o processo extensionista formativo, na constituição das encenações teatrais, que emergiu do trabalho coletivo de um grupo de professores da área de ensino de química da UFGD; que consideram o teatro científico como um eixo articulador entre ensino, pesquisa e extensão. Com isso, o enfoque adotado também está presente em componentes curriculares de Estágio em ensino e nos que tem em sua carga horária um percentual de Prática como Componente Curricular.

Participaram deste projeto acadêmicos dos cursos de Bacharelado em Química e Licenciatura em Química, além de pós-graduandos dos programas de pósgraduação em Química e do programa de pós-graduação em Ciência e Tecnologia Ambiental.

Inicialmente, após a aprovação do projeto, realizamos a divulgação entre os acadêmicos de graduação e pós-graduação. Com os interessados selecionados estabelecemos um cronograma para as reuniões a partir das seguintes etapas: (a) Reuniões de formação e orientação, realizada em todos os momentos do projeto; (b) Constituição das peças teatrais: duração de dois meses; e (c) Apresentação nas escolas durante o período de 18 meses. 
Foram organizados cinco grupos, respectivamente, constituídos por seis componentes. No total, participaram, aproximadamente, trinta acadêmicos e pósgraduandos.

As encenações teatrais foram desenvolvidas durantes os encontros e como resultado, apresentamos abaixo as etapas que possibilitaram a realização do projeto de extensão:

1. Reunião/formação inicial: Reunião inicial para apresentação da proposta projeto de extensão Show da Química por meio de teatro. Neste momento, foram explorados subsídios em que os participantes pudessem averiguar as possíveis contribuições para a formação docente ao realizar esta atividade na escola. A utilização de vídeos demonstrativos presentes na internet (you tube), ajudaram no entendimento do que é uma encenação teatral com a utilização de experimentos.

2. Seleção e adaptação de experimentos com impacto visual: Os participantes selecionaram e testaram laboratório, três ou quatro experimentos que continham "impacto visual", ou seja, boa visualização, mudança de cor, desprendimento de fumaça, formação de precipitado, entre outras evidências de que ocorreu uma reação química.

3. Elaboração de uma peça teatral: O grupo de participantes elaborou uma narrativa em que os possíveis experimentos se encaixem. Cabe ressaltar que essa atividade ocorre de forma articulada a de número dois. As narrativas constituíam por elementos como cena, instrumento, propósito, ato e agente. Esses elementos constituem o denominado quinteto dramatístico de Burke, no qual, a cena trata-se de quando e onde ocorreu a história, o instrumento contempla a nuance de como a história foi feita, o propósito refere-se ao porque esta história foi elaborada, o ato ao que estritamente foi descrito e o agente aos personagens envolvidos (DORNELES, 2011).

4. Segurança na realização do experimento. Durante os testes dos experimentos, os acadêmicos foram alertados sobre os procedimentos, minimizando as chances de ocorrência de acidentes.

5. Adequação do experimento: Os experimentos selecionados e testados foram adequados para o contexto escolar, mais especificamente, para sua realização em sala de aula.

6. Adequação para o tempo de apresentação: O tempo de apresentação de cada peça, não poderia ser muito extenso, para eu fosse possível a realização no tempo uma hora de aula na escola.

7. Músicas/trilhas sonoras/vinhetas: É essencial que essa etapa de elaboração seja construída de modo a se inserir no contexto da história, pois a utilização de música pode proporcionar momentos apreensão no público; criando um ambiente favorável para o desenvolvimento da peça e da interação com o público. 
DOI: $10.12957 / \mathrm{e}-m o s a i c o s .2019 .38208$

8. Explicação dos experimentos: A explicação dos fenômenos físico e químicos ocorridos nos experimentos é o momento em que ocorre a desmistificação dos conceitos científicos. Dessa forma, deve ser utilizada uma linguagem acessível ao aluno do Ensino Médio, mas ao mesmo tempo deve ser mantido o caráter científico da teoria.

9. Caracterização do cenário: Ao elaborar a encenação foi proposto um cenário para a realização da atividade. Neste caso, cadeiras, mesas e outras peças decorativas objetivavam atender à exigência da atividade, visto que, priorizamos a encenação e não ao cenário. Logo, cadeiras e mesas já caracterizavam muitos cenários das peças.

10. Caracterização dos figurinos: A caracterização dos personagens (figurinos) ocorreu de forma recorrente por meio de jalecos (característica do show da química) ou mesmo por acessórios (chapéus, roupas, etc).

11. Os Slides: A apresentação da encenação foi acompanhada por slides que contextualizavam os acontecimentos da peça teatral. Dessa forma, na elaboração dos slides existiam figuras e imagens que proporcionavam animação e humor nas apresentações. Além disso, os slides serviam de "roteiro virtual", para que os acadêmicos não se perdessem durante as apresentações.

12. Humor durante a apresentação: Para melhor dinâmica das apresentações foi apresentado, no meio da história interpretada, situações engraçadas, retiradas de bordões ou "memes" da internet, de forma a intensificar o caráter lúdico das encenações.

13. Roteiro: Todo o estudo para compor a apresentação foi sistematizado na forma de um roteiro, que pode seguir os seguintes itens: 1 - integrantes do grupo; 2 - nome da escola; 3 - título da peça; 4 - resumo da encenação; 5 - nome dos personagens; 6 - descrição do cenário; 7 - história a ser interpretada utilizando o experimento; 8 - materiais e reagentes necessários; 9 - procedimento experimental; 10 - medidas de segurança; 11 - fundamentação teórica do experimento e 12 bibliografia consultada.

14. Ensaio da apresentação: Momento destinado a ensaiar intensivamente a apresentação e ajustes em roteiro, experimento, postura, tom de voz, etc.

15. Apresentação: Apresentação e divulgação do teatro na universidade e escola da região.

A avaliação de cada etapa foi realizada nas reuniões de grupo. Todo a equipe envolvida argumentou em relação as atividades desenvolvidas, na qual, puderam expressar os desafios, condicionantes, aprendizados que acompanharam durante as atividades desenvolvidas. 


\section{RELATO DE EXPERIÊNCIA DAS ATIVIDADES DESENVOLVIDAS NA ESCOLA}

Neste cenário, desenvolvimentos dez encenações teatrais que focaram o desenvolvimento de atividades na Educação Básica.

Quadro 01: Relação dos locais de apresentação e quantidade de apresentações

\begin{tabular}{|c|l|c|}
\hline No & \multicolumn{1}{|c|}{ Locais de apresentação } & $\begin{array}{c}\text { Quantidade } \\
\text { de apresentações }\end{array}$ \\
\hline 1 & Escolas estaduais em Dourados & 20 \\
\hline 2 & Escolas em cidades do Mato Grosso do Sul & 6 \\
\hline 3 & Encontro de Formação continuada de professores & 2 \\
\hline 4 & Abertura de eventos & 3 \\
\hline & Total & 29 \\
\hline
\end{tabular}

Fonte: Os autores (2018).

No tocante as encenações teatrais, estas não se limitam a apresentação de experimento com viés puramente demonstrativo, ao contrário disso, pois nossa preocupação era proporcionar aos estudantes da educação básica o conhecimento científico envolvido em cada apresentação. A partir desse pensamento elaboramos as seguintes apresentações. Encenações teatrais produzidas ao longo das atividades:

A realidade por trás das histórias mais famosas - Nesta encenação alguns personagens de fiç̧ão e desenho, são "desmascarados", quando é revelado que suas "mágicas" ou "superpoderes", na verdade estão atrelados a conhecimentos químicos desenvolvidos em experimentos .

Química Alerta - A peça consiste em um programa policial no qual o apresentador "Magnésio Resende" relata um caso que ocorreu na cidade de Quimicolândia. Nesta situação, dois rapazes saem de um bar para comemorar a criação de um "novo material", sendo que um deles, recém habilitado é parado por policiais devido a sua péssima habilidade em dirigir o carro. Nesta abordagem os policiais revistam o carro encontram uma substância estranha e usam de experimentos químicos e seus conceitos para descobrir que tipo de substância é aquela.

Amiga da Onça - Conta a história de um casal que estão passando por crise no casamento e uma amiga sugere que ela vá a uma cartomante para tentar descobrir o motivo do desentendimento. Ao chegar na cartomante, se deparam com experimentos químicos, que serão utilizados para desvendar os mistérios que 
DOI: $10.12957 / \mathrm{e}-\mathrm{mosaicos} .2019 .38208$

sondam o seu casamento. E nesse impasse, ela tem uma grande descoberta que será revelada no decorrer da história.

Circo Hexano - Esta história se inicia com uma personagem chamada Amina, que resolve estudar química orgânica no meio da noite. Depois de tanto estudar, resolve assistir televisão. Então começa a trocar de canal até achar um programa chamado circo hexano, no qual, mágicos e palhaços fazem "mágicas". No entanto, Amina, percebe algo errado e irá desvendar o mistério dessas magicas, por meio de seus conhecimentos de química.

Assalto ao Banco - A peça conta a história de uma dupla de ladrões atrapalhados, que têm a ideia de assaltar um banco, mas sem saber ao certo como fazer isso. Logo, pesquisam rapidamente e criam uma estratégia de assalto em que eles acreditam que dará certo. Infelizmente, ou felizmente, os atrapalhados ladrões não realizam os experimentos de forma correta e o assalto vai por água abaixo.

Talk Show da Química - A peça retrata um Talk Show de Química, no qual, algumas celebridades irão realizar experimentos de química em um palco e serão julgadas por um jurado muito inteligente, mas todos atrapalhados. Ao final, a plateia escolherá qual o experimento que mais lhe chamou a atenção.

Deu a louca no laboratório - Essa peça tem como objetivo apresentar conceitos básicos de como se portar em um laboratório de química. Retrata a vida de estudantes que estão em sua primeira aula no laboratório. Como não se atentaram a cuidados básicos de segurança no laboratório, vários problemas começam a acontecer.

Casos na Química - Essa peça retrata diversos casos de família, no qual, as famílias, não aguentam mais o comportamento de seus filhos, que possuem algo em comum: todos são estudantes de química. Ao contar cada história, os filhos começam a realizarem experimentos de química no palco do programa.

Química das Sombras - A história passa-se em um período atual, no qual dois estagiários da polícia, Kelly e Bill estão encarregados de desvendar um crime, porém, além de possuírem poucos conhecimentos, são um pouco atrapalhados. No entanto, terá a ajuda de Sherlock Holmes e Dr. Watson, com a realização de experimentos de química para desvendar o crime.

Química CSI - A história é basicamente inspirada no programa de televisão CSI, no qual, acontece algo inesperado e um investigador se põe a resolver o caso em que todos em sua volta são suspeitos.

Todas as peças, após serem analisadas, são classificadas como teatro científico. As demonstrações experimentais fazem parte de uma proposta de melhoria do ensino de química e ciências no Ensino Médio, assim, foram acompanhadas de um roteiro experimental e a explicação do fenômeno no final. A explicação teórica procurou desmistificar os conceitos por meio de uma linguagem própria para o entendimento dos espectadores, potenciais aprendizes. Os conceitos 
DOI: $10.12957 / \mathrm{e}-$ mosaicos.2019.38208

científicos foram apresentados de forma lúdica e os textos permitiram com o público que estava assistindo as peças de teatro.

Dentre as características das encenações podemos citar: abordagem de conceitos científicos associados ao conteúdo disciplinar da educação básica; abordagem de conceito científicos interdisciplinares; desmistificação de conceitos científicos e temática relacionado a fatos do cotidiano.

A partir do contexto apresentado, apontamos a imprescindibilidade de ações desenvolvidas no âmbito da universidade ancorem-se em pilares como o ensino, a pesquisa e a extensão. Ao longo das atividades do projeto, fomos percebendo suas potencialidades dentro deste importante tripé. Sua natureza extensionista não inviabilizou que outras esferas fossem igualmente desenvolvidas, influenciando de forma positiva nas atividades vinculadas ao ensino e a pesquisa.

Não podemos restringir as ações do projeto supracitado ao momento culminante das apresentações, muito trabalho era desenvolvido nos bastidores. Momentos de escrita, leitura, pesquisa e planejamento constituíam a essência da proposta. Por meio dessa dinâmica complexa, articulavam-se as ações professores e alunos de diferentes espaços e componentes curriculares. Aspecto que gerou frutos significativos em contextos que não esperávamos. Os licenciandos relatavam que ao envolver-se nas ações do projeto suas atividades em Estágio eram potencializadas, sua interação com o ambiente escolar e com a comunidade se tornava mais profícua. O mesmo era percebido pelos professores que acompanhavam os Estágios, a relação com a escola e com os professores era fortalecida. Tais aspectos tornavam mais potentes os laços que unem a Universidade e a Escola.

Nesse sentido compreendemos que a contribuição deste espaço para os envolvidos oportuniza uma formação diferenciada, considerando as peculiaridades de trabalhar com a linguagem química para um público de "não químicos". Essa transposição do linguajar potencializa a compreensão do tema trabalhado pelos envolvidos e com o retorno do público estas ações podem ser redirecionadas. Ser professores nos parece um exercício constante de trabalhar com a linguagem, sendo assim, o desafio proposto nos insere em uma posição de constante exercício da habilidade de transposição didática.

A divulgação científica foi se configurando com a ação e meta mais presente, na medida em que as atividades eram desenvolvidas, problematizadas e reorganizadas. Fomos, enquanto grupo, entendendo melhor os movimentos que perpassavam esse objetivo maior de tornar mais acessível essa linguagem que muitas vezes só é conhecida e compreendida por poucos.

\section{CONSIDERAÇÕES FINAIS}

Nesse contexto, concordamos com Pereira e Santos (2017), que defendem a utilização de atividades de teatro de temática científica no processo de formação 
DOI: $10.12957 / \mathrm{e}-\mathrm{mosaicos} .2019 .38208$

docente; pois abre espaço para discussão de conceitos científicos e contribui na atuação do docente em formação no espaço escolar, de forma a potencializar o aprendizado de metodologias de ensino inovadoras.

Compreendemos, por meio do desenvolvimento das ações supracitadas, que o projeto se configurou como uma potente ferramenta de trabalho a partir do tripé ensino-pesquisa-extensão; intensificando a articulação entre Universidade e Escola, dando oportunidade para o desenvolvimento de saberes inerentes a ação docente que potencializaram as atividades desenvolvidas tanto por parte dos formadores quanto pelos acadêmicos em formação.

A apropriação de diferentes gêneros discursivos e a transposição da linguagem científica também se destacam como frutos significativos do projeto, elementos que oportunizaram um repensar dos princípios dos cursos que tencionam formar profissionais no campo da Química. Mais do que formar profissionais aptos ao mercado de trabalho, precisamos instrumentalizá-los para um diálogo profícuo para com aqueles que não pertencem a mesma zona de atuação, ou seja, para a comunidade em sua amplitude.

\section{REFERÊNCIAS}

BABIN, P.; KOULUMDJIAN, M. Os novos modos de compreender. Geração do audiovisual e do computador. São Paulo: Ed. Paulinas, 1989.

BOAL, A. Jogos para atores e não atores. Rio de Janeiro: Civilização Brasileira, 2005.

CARDOSO, S. P.; COLINVAUX, D. Explorando a motivação para estudar química. Revista Química Nova, n. 23, 2000.

CHASSOT, A. Alfabetização científica: questões e desafios para a educação. Ijuí: Unijuí, 2003.

DORNELES, A. M. A roda dos bordados da formação: o que bordam as professoras de química nas histórias de sala de aula?. Dissertação - Programa de Pós-Graduação em Educação em Ciências: Química da vida e Saúde. Universidade Federal do Rio Grande, Rio Grande, 2011.

JAPIASSÚ, R. Metodologia de Ensino de Teatro. Campinas: Papirus, 2001.

PEREIRA, A. S.; SANTOS, P. M. Contribuições do teatro científico para a formação inicial docente em química. Perspec. Dial.: Rev. Educ. e Soc., Naviraí, v. 4, n. 7, 2017. p. 130-149.

PESSOA, W. R.; ALVES, J.M. Motivação para estudar química: configurações subjetivas de uma estudante do segundo ano do ensino médio. Anais do VIII 
DOI: $10.12957 / \mathrm{e}-\mathrm{mosaicos} .2019 .38208$

Encontro de Pesquisa em Educação em Ciências. Disponível em http://www.nutes.ufrj.br/abrapec/viiienpec/resumos/R0164-1.pdf. Acesso em 20 de junho de 2018.

PINTRICH, P.R.; SCHUNK, D.H. Motivación en contextos educativos. Teoría, investigación y aplicaciones (2a ed.). Madrid: Pearson Educación. 2006.

SPOLIN, V. Improvisação para o teatro. São Paulo: Perspectiva, 1998.

ITURBE, T. Teatro para ser representado na escola. São Paulo: Madras, 2007.

Recebido em 08 de novembro de 2018.

Aceito em 25 de maio de 2019.

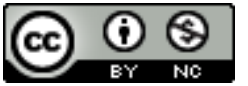

A e-Mosaicos Revista Multidisciplinar de Ensino, Pesquisa, Extensão e Cultura do Instituto de Aplicação Fernando Rodrigues da Silveira (CAp-UERJ) está licenciada com uma Licença Creative Commons - Atribuição-NãoComercial 4.0 Internacional.

Os direitos autorais de todos os trabalhos publicados na revista pertencem ao(s) seu(s) autor(es) e coautor(es), com o direito de primeira publicação cedido à e-Mosaicos.

Os artigos publicados são de acesso público, de uso gratuito, com atribuição de autoria obrigatória, para aplicações de finalidade educacional e não-comercial, de acordo com o modelo de licenciamento Creative Commons adotado pela revista. 